\title{
Enteral tube feeding in adults
}

\author{
${ }^{1} \mathrm{R}$ Scott, ${ }^{2} \mathrm{TE}$ Bowling \\ ${ }^{1}$ Specialist Registrar in Gastroenterology; ${ }^{2}$ Consultant in Gastroenterology and Clinical Nutrition, Nottingham University Hospitals, \\ Nottingham, UK
}

\begin{abstract}
Enteral tube feeding is usually a relatively straightforward method of nutritional support, and should be facilitated by a multiprofessional team. For short-term use $(<4$ weeks) a fine bore feeding nasogastric tube is indicated but if longer term feeding is required then a gastrostomy is appropriate, usually inserted endoscopically (a percutaneous endoscopic gastrostomy tube). The most common serious complication of a nasogastric tube is not identifying a misplaced tube within the lungs: there are clear recommendations from the National Patient Safety Agency as to how to check tube placement. Nasojejunal tubes are required in patients with gastroparesis. Tube blockage is common and is prevented by careful and regular flushing.
\end{abstract}

Diarrhoea is the most complication of feeding and is often related to other medication. Clinicians need an algorithm for systematically dealing with such a problem. Refeeding syndrome may occur in malnourished patients and is characterised by low levels of potassium, phosphate, and/or magnesium, as well as disorders of water and salt balance. Identifying the at-risk patient with careful monitoring is crucial.

KEYWORDS complications, enteral tube feeding, gastrostomy, nasoenteral tubes

DECLARATION OF INTERESTS No conflict of interests declared
Correspondence to T Bowling Queen's Medical Centre Campus Nottingham University Hospitals NHS Trust

Nottingham NG7 2UH

UK

e-mail tim.bowling@nuh.nhs.uk

\section{OVERVIEW}

\section{Definition}

Enteral tube feeding is the delivery of nutritionally complete feed directly into the stomach or small intestine via a tube.

\section{INDICATIONS}

Enteral tube feeding is indicated in any patient who cannot meet their nutritional requirements by oral intake and who has a functioning and accessible gastrointestinal tract. It can be administered either into the stomach or directly into the small intestine (usually the jejunum). Table I shows examples of when enteral feeding is indicated.

\section{Routes}

The following options are available:

- Nasogastric tube

- Nasojejunal tube

- Gastrostomy

- Percutaneous endoscopic gastrostomy (PEG)

- Radiological inserted gastrostomy (RIG)

- Surgical

- Jejunostomy

- $\quad$ Endoscopic (PEJ or PEGJ)

- Radiological

- Surgical
TABLE I Indication for enteral feeding

\begin{tabular}{|c|c|}
\hline $\begin{array}{l}\text { Patients with a } \\
\text { functioning stomach } \\
\text { and/or intestine }\end{array}$ & $\begin{array}{l}\text { Supplement inadequate } \\
\text { oral intake }\end{array}$ \\
\hline $\begin{array}{l}\text { - } \quad \text { Impaired swallow, e.g. } \\
\text { stroke, motor neurone } \\
\text { disease, Parkinson's } \\
\text { disease } \\
\text { - } \\
\text { Altered level of } \\
\text { consciousness, making } \\
\text { oral feeding impossible } \\
\text { - } \quad \text { Ventilated patients } \\
\text { - } \quad \text { Dysphagia with oro- } \\
\text { pharyngeal/oesophageal } \\
\text { obstruction, i.e. } \\
\text { head and neck and } \\
\text { oesophageal cancer } \\
\text { Gastric outlet } \\
\text { obstruction: Mechanical } \\
\text { (tumour, pyloric } \\
\text { stricture) or functional } \\
\text { (stasis). These situations } \\
\text { will require jejunal } \\
\text { feeding (see below) } \\
\text { Severe pancreatitis } \\
\text { (gastric or jejunal) }\end{array}$ & $\begin{array}{ll}\text { - } & \text { Cystic fibrosis } \\
\text { - } & \text { Hyper-catabolic } \\
& \text { states, e.g. burn injury, } \\
& \text { decompensated liver } \\
& \text { disease } \\
\text { - } & \text { Facial injury } \\
\text { - } & \text { HIV wasting } \\
\text { - } & \text { Psychological/ } \\
& \text { psychiatric reasons, e.g. } \\
\text { anorexia nervosa }\end{array}$ \\
\hline
\end{tabular}

\section{NASOGASTRIC TUBES}

Nasogastric tubes (NGTs) are recommended for those requiring tube feeding for no longer than 4-6 weeks. 
They are safe, cost effective, and less invasive than alternatives. There are two types of NGT: fine bore tubes designed for administration of feed; and wide bore tubes (e.g. Ryles) designed for aspiration. The latter can cause oesophageal damage, such as ulceration and stricture, if left in for a prolonged period, and should not normally be used for feeding. Fine bore tubes are usually easy to insert and safe, even in patients with oesophageal varices. They should not be inserted in patients with obstructive pathology in the nasopharynx or oesophagus, or in patients with basal skull fractures.

The National Patient Safety Agency issued guidance in 2005 for safe placement and position checking of nasogastric tubes. The guidance highlighted the unreliability of certain tests - such as the 'whoosh' test and testing for acidity with litmus paper - and instead recommended testing with $\mathrm{pH}$ indicator paper as the first line check $(\mathrm{pH}=5.5)$. Higher $\mathrm{pH}$ suggests either the position could be wrong or the patient could be on a proton pump inhibitor. It recommended checking X-ray images as the second line test, although not for routine use. Since 2005, the single greatest cause of harm resulted from misinterpretation of X-ray images. The National Patient Safety Agency therefore issued a further safety alert in March $201 \mathrm{l}$ focusing on safe interpretation of X-ray images. Tube placements should be checked at least once daily and before administering each feed or medication. However, there has to be an element of pragmatism in this. Provided that the initial placement was appropriately confirmed and no other signs of dislodgement (such as retching or coughing) are present, repeat radiography would not usually be needed as long as the external length of tube remains unchanged.

The most commonly encountered problem with a NGT is inadvertent removal, either by the patient or by accident, e.g. snagged on clothing or vomiting. If this is a recurring problem and feeding is still required, either a PEG can be considered or a 'nasal loop' or bridle can be attached, thereby making accidental removal far less likely - $18 \%$ for bridled tubes compared to $63 \%$ for nonbridled tubes in one study - with the bridled group more likely to meet their recommended nutritional requirements. Bridle systems are commercially available and, although their unit cost is relatively high, this is more than offset by the avoidance of repeated NGT placements +/- X-rays to verify placement. For other complications of both NGTs and nasojejunal tubes see Table 2.

\section{NASOJEJUNAL TUBES}

Specifically designed self-propelling nasojejunal tubes such as the Bengmark tube (Nutricia, Trowbridge, UK) or Tiger TubeTM (Cook Medical Inc, Indiana, USA) will spontaneously cross the pylorus in $70-80 \%$ of patients
TABLE 2 Complications of nasogastric and nasojejunal tubes (common complications in bold)

\begin{tabular}{|c|c|}
\hline Complications & Explanation \\
\hline Removal by patient & $\begin{array}{l}\text { Purposeful: consider patient } \\
\text { withdrawal of consent } \\
\text { Confused: may need re-siting } \\
\text { or if repeated removal consider } \\
\text { nasal loop/bridle or alternative } \\
\text { means of nutritional support, } \\
\text { e.g. PEG }\end{array}$ \\
\hline $\begin{array}{l}\text { Oesophageal ulceration } \\
\text { or strictures }\end{array}$ & $\begin{array}{l}\text { Uncommon if fine-bore tubes } \\
\text { are used }\end{array}$ \\
\hline Malposition & $\begin{array}{l}\text { Malposition into lungs can } \\
\text { lead to infection, effusion and } \\
\text { empyema. Occasionally tube can } \\
\text { be malpositioned intracranially. } \\
\text { Correct verification of tube } \\
\text { position should avoid this. }\end{array}$ \\
\hline Aspiration & $\begin{array}{l}\text { Minimised by feeding for no } \\
\text { more than } 20 \text { hours per day at } \\
\text { an elevation of at least } 30^{\circ} \\
\text { Aspiration of gastric contents in } \\
\text { to the bronchial tree occurs for } \\
\text { most patients on intragastric } \\
\text { feeding, but fortunately clinical } \\
\text { events are not as commonplace. } \\
\text { However, patients do need to } \\
\text { be monitored for clinical signs } \\
\text { of respiratory tract infection } \\
\text { and treated appropriately with } \\
\text { antibiotics if this occurs. It } \\
\text { may also be necessary to stop } \\
\text { the intragastric feeding and } \\
\text { consider post-pyloric feeding. }\end{array}$ \\
\hline Blockage & $\begin{array}{l}\text { All types of enteral feeding } \\
\text { tubes may become blocked and } \\
\text { fine bore tubes are particularly } \\
\text { at risk. Tubes should be flushed } \\
\text { with water before starting and } \\
\text { after completion of a feed, 4-6 } \\
\text { hourly throughout feeding and } \\
\text { before and after medication, } \\
\text { as residue can quickly build } \\
\text { up. If blocked, soda water or } \\
\text { pancreatic enzymes, which } \\
\text { break down coagulated protein, } \\
\text { can be used.Acidic fizzy drinks, } \\
\text { such as cola, can coagulate } \\
\text { protein in the tube and } \\
\text { exacerbate the problem - these } \\
\text { are no longer recommended. }\end{array}$ \\
\hline
\end{tabular}

with normal gastroduodenal motility, especially with a concurrent intravenous bolus of metoclopramide. If the stomach is atonic, nasojejunal tubes usually require endoscopic placement. The distal end must be placed beyond the duodenojejunal flexure or it will invariably pass retrogradely back into the stomach. There are 
other systems that can facilitate transpyloric passage, e.g. Cortrak (Corpak MedSystems, Illinois, USA), where an electromagnetic device on the end of the tube can be tracked by a bedside imaging system to help ensure correct placement. Plain abdominal X-ray is required to verify placement, unless placed under screening. Nasojejunal tubes come as single, double or triple lumen; double or triple lumen tubes are recommended for patients who require simultaneous gastric decompression and small bowel feeding.

\section{GASTROSTOMY}

A gastrostomy is usually preferred if tube feeding is likely to be required for greater than 4-6 weeks. It can be placed endoscopically (PEG); radiologically (RIG) or occasionally surgically. There are a number of different types of PEG/RIG tubes in terms of size (9 FG-30 FG), internal fixator (flange, balloon) and material, including more cosmetically acceptable 'button' gastrostomies. If the anatomy prevents insertion by one method then other methods will be limited by the same problem. PEG tube insertion is usually straightforward. Although not a sterile procedure, antibiotic prophylaxis $(2 \mathrm{~g}$ cefotaxime or $1.2 \mathrm{~g}$ co-amoxiclav) is recommended. Table 3 lists the contraindications to PEG insertion. It should be noted that many of the 'relative contraindications' to endoscopic placement can be overcome if insertion is done under radiological guidance.

PEGs and RIGs can be easily taken out, but care is required. If removed within 2-3 weeks of insertion a formal tract may not have formed, with consequent risk of spillage of gastric contents into the peritoneal cavity leading to peritonitis. This is especially likely in patients who are severely undernourished, having chemotherapy or taking steroids. This also means that it is not possible, in these first weeks, to re-insert a feeding tube down the same track, as it will not find its way into the gastric lumen. Therefore if the PEG/RIG does come out in the first few weeks of insertion the stoma site should be covered, antibiotic cover instituted and, if nutritional support is still required, an alternative, e.g. a NGT, used until the wound has healed. After 2-3 weeks removal presents little risk of peritonitis or sepsis. However, closure is rapid, so if a replacement is required this must be done within 4-6 hours using a fresh PEG/RIG or, temporarily, a balloon gastrostomy or Foley catheter. Elective removal is usually undertaken endoscopically, depending on the specific design of the tube used. Alternatively, the tube can be cut close to the skin allowing the internal fixator to pass spontaneously through the gastrointestinal tract. There are a few reported incidents of obstruction, e.g. at the ileocaecal junction, and therefore some experts are wary of this method of removal. This should not be undertaken if there is known small intestinal pathology, such as strictures.
TABLE 3 Contraindications to PEG insertion

\begin{tabular}{|c|c|}
\hline Absolute & Relative \\
\hline $\begin{array}{ll}\text { - } & \text { Inability to pass } \\
\text { endoscope due to } \\
\text { obstructing pathology } \\
\text { in oropharynx or } \\
\text { oesophagus* } \\
\text { - } \quad \text { Obstructing gastric } \\
\text { outflow pathology } \\
\text { - } \quad \text { Significant ascites } \\
\text { Gastric varices }\end{array}$ & 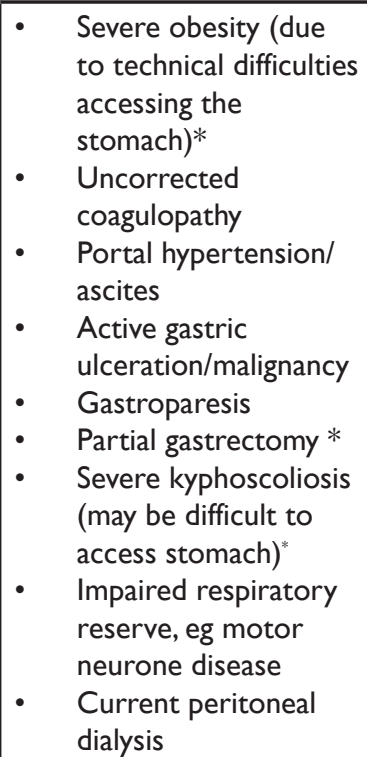 \\
\hline
\end{tabular}

"May be achievable if done under radiological guidance to locate stomach.

\section{JEJUNOSTOMY}

Percutaneous endoscopic gastrojejunostomies (PEGJ) are 'extensions' that attach to a PEG and can be passed endoscopically beyond the duodenojejunal flexure. PEJ is similar to PEG but requires a direct puncture into the small intestine. Insertion techniques are not straightforward and, on the whole, there is probably no advantage of these over a surgically placed jejunostomy for postpyloric feeding, except in a patient who is too unfit to have a general anaesthetic.

Removal and complications of PEGJ/PEJ are similar to PEG (Table 4).

Surgical jejunostomies are most commonly needle catheter jejunostomies inserted subserosally to reduce the risk of leakage, but tend to be fine bore, and prone to block if poorly managed. Other tubes such as Foley catheters can be used but are not recommended because of leakage and difficulties in connecting with feeding equipment. Increasingly, jejunostomies are inserted peri-operatively to allow for early postoperative feeding. Although complications can occur, the advantages of improved postoperative nutrition usually outweigh the risks.

\section{DELIVERY OF ENTERAL FEED}

Feed can be administered as a bolus or continuously. Continuous feeding is usually over 16-18 hours; bolus feeds are typically $100-500 \mathrm{ml}$ of feed over $15-60$ 
TABLE 4 Complications of feeding stomas (PEG, PEGJ and PEJ) (common complications in bold)

\begin{tabular}{|c|c|}
\hline Early & Late \\
\hline $\begin{array}{l}\text { Pain: Common within first } 24 \text { hours. If severe } \\
\text { exclude peritonitis/tube displacement into anterior } \\
\text { abdominal wall } \\
\text { - Haemorrhage: Unusual if clotting screen within } \\
\text { normal limits. As malnutrition can lead to vitamin K } \\
\text { deficiency, the prothrombin time/INR should always } \\
\text { be checked prior to procedure } \\
\text { - Peritonitis } \\
\text { - Pneumoperitoneum:There will always be some free } \\
\text { air after PEG insertion } \\
\text { Gastrocolic fistula due to interposition of colon } \\
\text { between anterior abdominal wall and stomach }\end{array}$ & $\begin{array}{l}\text { - Stoma infection: Usually resolves with appropriate } \\
\text { antibiotics, e.g. flucloxacillin and proper stoma care. } \\
\text { Not usually necessary to remove PEG or stop } \\
\text { feeding unless severe ulceration or wound } \\
\text { breakdown } \\
\text { Tube blockage: Minimised if flushed with water } \\
\text { before and after each feed/medication. See NGT } \\
\text { blockage in Table } 2 \\
\text { Aspiration: Minimised by feeding for no more than } \\
20 \text { hours per day at an elevation of at least } 30^{\circ} \text {. } \\
\text { Buried bumper: Migration of internal fixator } \\
\text { migrates into gastric/anterior abdominal wall } \\
\text { leading to tube blockage. This can often be } \\
\text { managed endoscopically, but can require surgery } \\
\text { to remove } \\
\text { Tumour tract seeding:A few case reports of PEG's } \\
\text { inserted in oesophageal or oro-pharyngeal } \\
\text { tumours developing neoplastic seeding in stoma } \\
\text { tracks. Where the PEG is inserted as part of } \\
\text { palliative care, this is unlikely to be of relevance in } \\
\text { the patient's life-time } \\
\text { Overgranulation: Can occur at stoma site and } \\
\text { bleed/become painful. Treated with steroid cream } \\
\text { or silver nitrate } \\
\text { Mortality: } 30 \text { day mortality of } 6 \% \text { was reported in } \\
\text { the NCEPOD } 2004 \text { but other recent studies } \\
\text { identified mortality rate of } 3.3-18.2 \% \text {.This be } \\
\text { reduced with better patient selection. }\end{array}$ \\
\hline
\end{tabular}

minutes at 3-6 hour intervals. Bolus feeding into the stomach is more physiological. Although there is a perception that it predisposes to aspiration, diarrhoea, bloating and dumping syndrome compared to continuous feeding, there is no clinical evidence to indicate that this is the case. With jejunal feeding, the loss of the stomach reservoir means patients with post-pyloric tubes are usually fed continuously.

\section{OTHER COMPLICATIONS ASSOCIATED WITH ENTERAL FEEDING}

In addition to complications associated with the tubes themselves and with their insertion, enteral feeding can also cause gastrointestinal problems, such as diarrhoea, nausea and vomiting, reflux and metabolic abnormalities such as refeeding syndrome and various electrolyte disturbances.

\section{GASTROINTESTINAL PROBLEMS}

\section{Diarrhoea}

This can be problematic and sometimes difficult to manage. The incidence can be as high as $60 \%$ in critical care. Luft et al. showed an incidence of $18 \%$ among patients on medical and surgical wards receiving enteral nutrition compared to $6 \%$ in matched controls. The causes are multifactorial and include concomitant medication (especially antibiotics and laxatives) and (rarely) contaminated feeds. Management should include a review and rationalisation of medication; stool cultures for Clostridium difficile and other infective organisms; and exclusion of other causes of diarrhoea.Treatment should concentrate on symptomatic control with loperamide and codeine. Slowing down the feed rate and using a low volume/high calorific content feeds, changing to a different mode of delivery (continuous, bolus, etc.) or introducing fibre to the diet can sometimes be successful. Only in the most severe cases would consideration of parenteral feeding be appropriate.

\section{Vomiting/aspiration/reflux}

Both nasogastric and PEG feeding increase the risk of aspiration. Where possible patients should be fed at a $30-45^{\circ}$ angle. Standard anti-emetics and prokinetic agents can be effective. Alternative or additional management options include alteration of feed delivery (change from bolus to continuous feeding), changing diet to a more energy-dense one with smaller volumes delivering equivalent calories, and considering postpyloric feeding, because of the lower risk of aspiration. 


\section{METABOLIC COMPLICATIONS}

A deficiency or excess of any macro or micronutrient could be caused by enteral feeding, and close monitoring of patients is essential. The most common problem is refeeding syndrome, which can occur if feed in a malnourished patient is introduced at too high a rate. It is characterised by cardiac arrhythmias, electrolyte disturbance and may progress to multi-organ failure. Refeeding syndrome can be fatal usually due to hypophosphataemia or heart failure. An anabolic drive secondary to excessive calories leads to an increased intracellular uptake of phosphate, magnesium and potassium leading to deficiencies in these electrolytes in the extracellular compartment. There is also often an imbalance in sodium and water balance along with thiamine deficiency. To avoid it requires a slow start to feeding, as low as $5-10 \mathrm{kcal} / \mathrm{kg} /$ day in the most severely malnourished, and very careful monitoring and correction of electrolyte imbalance. A more detailed description of this condition can be found in a review by Boateng et al.

\section{FURTHER READING}

I Boateng AA, Sriram K, Meguid M et al. Refeeding syndrome: treatment considerations based on collective analysis of literature case reports. Nutrition 20 10;26: I 56-67.http://dx.doi.org//0.1016/j. nut.2009.II.017

2 Brandt CP, Mittendorf EA. Endoscopic placement of nasojejunal feeding tubes in ICU patients. Surg Endosc 1999; I3: I21 I-14.

3 Luft VC, Beghetto MG, de Mello ED et al. Role of enteral nutrition in the incidence of diarrhea among hospitalized adult patients. Nutrition 2008; 24: 528-35. http://dx.doi.org//0.1016/j. nut.2008.02.004

Scoping our practice. London: NCEPOD; 2004. http://www.ncepod org.uk/2004sop.htm (accessed 24/2/2015).

5 National Institute for Health and Care Excellence. Clinical Guideline 32. Nutrition support in adults: oral nutrition support, enteral tube feeding and parenteral nutrition. London: NICE; 2006.

6 Reducing the harm caused by misplaced nasogastric feeding tubes in adults, children and infants. National Patient Safety Agency; $201 \mathrm{I}$. http://www.nrls.npsa.nhs.uk/alerts/?entryid45=129640 (accessed 23/2/2015)

\section{THE COLLEGE JOURNAL PRIZE}

The College Journal Prize 20I4, sponsored by the Senior Fellows' Club, has been won by B Quinn et al for their paper 'A masquerading mass: an unusual presentation of IgG4related systemic disease with tubulointerstitial nephritis'. This paper can be read in issue 2 , 2014 at http://www.rcpe.ac.uk/sites/default/files/harty.pdf

A prize of $£ 250$ will be awarded to the first-named (or corresponding) author of an original research paper on a clinical topic, deemed by a panel of judges to be the best paper by a doctor-in-training (i.e. pre-consultant level) published in The Journal of the Royal College of Physicians of Edinburgh in issues 3 and 4, 2014 and issues I and 2, 20I5. The paper will be selected by a panel of judges, including a senior Fellow, an active clinician and a member of the Editorial team. The prize-winner will be invited to give a short oral presentation based on his/her paper at the Trainees and Members' symposium in October 2015.

Further details may be obtained from the Editorial Office, RCPE, 9 Queen Street, Edinburgh EH2 IJQ, tel +44 (0) I 3 I 2473666 or email editorial@rcpe.ac.uk. 


\section{SELF-ASSESSMENT QUESTIONS}

\section{Enteral tube feeding in adults}

I. A 48-year-old man has recently been diagnosed with nasopharyngeal cancer, having presented to his GP with weight loss, hoarse voice and odynophagia. He is awaiting surgery followed by radiotherapy. He is not acutely unwell; he is selfemployed and is keen to continue working.

Which ONE of the following is the best means to provide him with nutrition?

A. Oral feed with food supplements

B. Nasogastric tube with intermittent feed

C. Nasojejunal tube with intermittent feed

D. Insertion of PEG or RIG

E. Provision of home total parenteral nutrition

2. A 54-year-old woman with relapsing and remitting multiple sclerosis is admitted by her community team who are anxious her PEG site may be infected. She is a bit more agitated than usual with a low grade pyrexia $\left(38.0^{\circ} \mathrm{C}\right)$. Cardiovascular and respiratory examinations are unremarkable. Her abdomen is soft and non-tender.There is well-demarcated spreading erythema, which is warm, surrounding the PEG site. There is a little frank pus around the PEG itself. She also has a suprapubic catheter which had been changed two weeks previously, the site of which looks clean. You note that this is the third admission this year with an infected PEG site.

Which ONE of the following is the most appropriate action to take once the wound is swabbed?

A. Start IV flucloxacilin and continue using the PEG

B. Start IV flucloxacillin and stop using the PEG

C. Replace the PEG and start IV flucloxacillin

D. Remove the PEG

E. Remove the PEG and start IV flucloxacillin

\section{A 60-year-old man with background hypertension was} admitted to the stroke ward following an ischaemic stroke. His swallowing was assessed to be unsafe and at risk of aspiration by the speech and language therapist. He was started on nasogastric feeding. Unfortunately, five days later he developed severe diarrhoea with his bowels opening more than ten times a day. His medications included simvastatin, aspirin, indapamide and perindopril. He developed skin excoriations around the sacrum and the groin and looked depressed. Otherwise, he remained clinically stable. Three stool samples were negative for Clostridium difficile or any other infective organism. The rate of delivery of feed was decreased and he had a week of codeine phosphate and loperamide without any improvement in the diarrhoea.

Which ONE of the following is the next most appropriate step in the management of his diarrhoea?

A. Liaise with the dietitian and consider changing him to either a bolus feeding regime or slowing the rate of feeding down using a low volume/high caloric content feed, and also increasing his dose of loperamide/codeine phosphate
B. Stop his NG feed, and insert an NJT for feeding C. Stop his NG feed, and insert a PEG for feeding D. Stop his NG feed, and start TPN temporarily and insert a NJT for long-term feeding

E. Stop his NG feed, give him IV fluid temporarily and after a few days re-introduce the NG feed at much slower rate

\section{Parenteral nutrition}

I.The nutrition support team were asked to review a number of patients on their ward round for consideration of starting PN.

In which ONE of the following should parenteral nutrition definitely be considered?
A.Anastamotic leak four days following limited small bowel resection of chronic stricture in Crohn's disease B. Dysphagia six days after a stroke
C. Flare up of inflammatory stricture in small bowel
Crohn's disease, unresponsive to oral steroids
D. Nausea following extensive small bowel resection for ischaemia, leaving behind $180 \mathrm{~cm}$ of small bowel and entire colon
E. Paralytic ileus, two days post procto-colectomy for rectal cancer

2. A patient admitted to hospital undergoes abdominal surgery for bowel resection due to superior mesenteric artery thrombosis. The operation is complicated by an anastamotic leak, for which he has been started on intravenous antibiotics and referred for consideration of parenteral nutrition. He has poor venous access.

Which ONE of the following would be considered the most appropriate form of venous access for his needs?
A. Dual lumen PICC line.
B. Peripheral cannula.
C. Single lumen central venous catheter (CVC).
D. Totally implanted venous access device (Portacath).
E. Tunneled central venous line (Hickman).

3. A patient on long-term home parenteral nutrition presents to A\&E with a pyrexial illness, but no focal symptoms. His heart rate and blood pressure are within normal limits. A diagnosis of catheter related blood stream infection is suspected.

Which ONE of the following is the most appropriate immediate management?

A. Central and peripheral blood cultures.

B. Discharge home on oral antibiotics.

C. Empirical intravenous antibiotics.

D. Immediate removal of line.

E. Monitor, while continuing to use the line for PN.

This paper was originally published as part of the Nutrition module on the RCPE Online Education Portal. Specialty Modules for continuing medical education, including the answers to these questions, are available to Fellows and Members at http:/llearning.rcpe.ac.uk 